\title{
Are COL1A1 gene polymorphisms associated with anterior cruciate ligament tear in the Indian population? Results of a preliminary case-control study
}

\author{
Sharad Prabhakar ${ }^{1}$ \\ Rakesh John ${ }^{1}$ \\ Mandeep S Dhillon ${ }^{1}$ \\ Akshay Anand ${ }^{2}$ \\ Kaushal Sharma ${ }^{2}$ \\ Sridar Bammidi²
}

1 Department of Orthopaedics, Post Graduate Institute of Medical Education and Research (PGIMER), Sector 12, Chandigarh

2 Centre for Systems Biology and Bioinformatics, Panjab University, Sector-25, Chandigarh

Corresponding author:

Akshay Anand

Neuroscience Research Laboratory

Department of Neurology

Post Graduate Institute of Medical Education and

Research (PGIMER)

Sector 12, Chandigarh 160012

E-mail: akshay2anand@gmail.com

\section{Summary}

Introduction: Despite the identification of various intrinsic and extrinsic risk factors associated with ACL tear, the exact etiopathogenesis of ACL tear is still incompletely understood. The evidence for association of COL1A1 gene polymorphisms with ACL tear has been somewhat conflicting.

Objective of the study is: to determine if rs1800012 and rs1107946 polymorphisms of COL1A1 gene are associated with ACL tear in an Indian population study group.

Methods: Fifty clinically, radiologically and surgically-proven ACL deficient patients and 52 healthy controls were included in the study. After isolation of DNA from peripheral blood monocytes, real time PCR was carried out to genotype COL1A1 rs1800012 and rs1107946 polymorphisms.

Results: Both the groups were matched for age and sex. Hardy Weinberg equilibrium was maintained for both genotypes. There was no signifi- cant difference in the genotype or allele distribution between the case and control groups for both rs1800012 $(p=0.516)$ and rs1107946 polymorphisms ( $p=0.971$ for $G T$ and $p=0.823$ for TT) in this preliminary study.

Conclusion: The rs1800012 polymorphism of COL1A1 gene remains the first and most extensively tested gene polymorphism for its association with ACL tear. Under-representation of the TT genotype has been observed in Swedish and South African Caucasian populations with ACL tear. This has not been noted in the Polish Caucasian population and in our study. More studies with larger study samples from different ethnic populations are needed before COL1A1 gene polymorphism screening tests are incorporated into ACL tear prevention programs.

Level of evidence: III b (case-control study).

KEY WORDS: anterior cruciate ligament (ACL), COL1A1 gene, single nucleotide polymorphism, genotype frequency, allele frequency.

\section{Introduction}

Anterior cruciate ligament (ACL) tear is one of the most common ligament injuries of the $\mathrm{knee}^{1,2}$. The etiology of ACL tear has been proven to be multifactorial $^{3,4}$. Although various intrinsic and extrinsic risk factors and their complex interaction have been identified and explored in great detail, the exact etiopathogenesis of ACL tears has not yet been entirely deciphered ${ }^{3}, 4$.

Over the last decade, 33 different single nucleotide polymorphisms (SNPs) of various genes have been investigated for association with ACL tear ${ }^{5-7}$. COL1A1 rs1800012 polymorphism was the first specific gene polymorphism to be positively associated with $\mathrm{ACL}$ tear $^{3,4}$. It is also the most extensively investigated SNP in the literature with various research teams having investigated the association between $C O L 1 A 1$ SNPs and ACL tear in different Caucasian population subsets with mixed results ${ }^{5-8}$. However, till date, there is no data from the Asian continent on the association of COL1A1 SNPs and ACL tear"

We conducted a genetic association, case-control study to investigate the association between SNPs of COL $1 A 1$ gene and ACL tear in the Indian population. 


\section{Materials and methods}

This study was carried out at the Postgraduate Institute of Medical Education and Research (PGIMER), Chandigarh, India after obtaining clearance from the institutional ethics committee. An informed, written consent was obtained from subjects of both case and control groups. The study has been conducted ethically according to accepted international standards and meets the ethical standards of the journal ${ }^{9}$.

\section{Recruitment of participants}

Fifty patients with clinico-radiologically and surgically proven ACL tear were enlisted into the study group from July 2012 to December 2013. The inclusion criteria were: I) age between $18-40$ years; II) no multiligament injuries or signs of knee osteoarthritis; III) no associated comorbidities. Fifty-two subjects with normal knees with no history of ligament/tendon injuries were recruited as control subjects. All participants underwent a thorough physical examination and completed a comprehensive proforma containing demographic details, mode of injury, relevant past, personal and family histories along with details of participation in sports. The participants who have only ACL injury were included in the study. The diagnosis was confirmed by both MRI and intra-operatively during diagnostic arthroscopy. Multi-ligament injuries were excluded from the study.

Experimentations pertaining to the study were performed in Neuroscience Research Lab (NRL), Department of Neurology, PGIMER, Chandigarh, India which follows good laboratory practices (GLP).

All experiments were performed using pre-calibrated instruments; quality assurance norms and established standard operating protocols (SOP) were adhered to. Records were maintained in Data Recording Sheets (DRS) by qualified research scholars; as prescribed by the OECD (Organisation for economic co-operation and development) guidelines, the investigators were blinded to the samples.

\section{DNA extraction}

Venous blood (5 ml) was drawn into an ethylenediaminetetraacetic acid (EDTA) vaccutainer and stored at room temperature for 2 hours to allow sedimentation of red blood cells. The upper layer was then aspirated and placed over the same amount of ficoll paque solution (Amersham Biosciences, USA) followed by centrifugation at $1800 \mathrm{rpm}$ for 30 minutes. After centrifugation, the peripheral blood monocytes (PBMC) settle as a thin middle layer; the PBMC were separated and kept in a separate tube. The PBMC was now subjected to centrifugation at $5000 \mathrm{rpm}$ for 5 minutes, washed with phosphate-buffered saline (PBS) and processed for DNA isolation. Next, the genomic DNA was isolated using commercially-available QIAGEN DNeasy kit. Ultraviolet-visible spectrophotometry (Backman Coulter) was used to quantify the DNA. Electrophoresis on 1\% agarose gel (Biorad) was performed to validate the quality of DNA (Fig. 1).

\section{COL1A1 genotyping}

RT-PCR (real-time polymerase chain reaction) was used to analyse SNPs and a 48-well StepOne ${ }^{\mathrm{TM}}(A p$ plied Biosystems Inc, Foster City, USA) RT-PCR instrument was used for the same. RT-PCR was car-

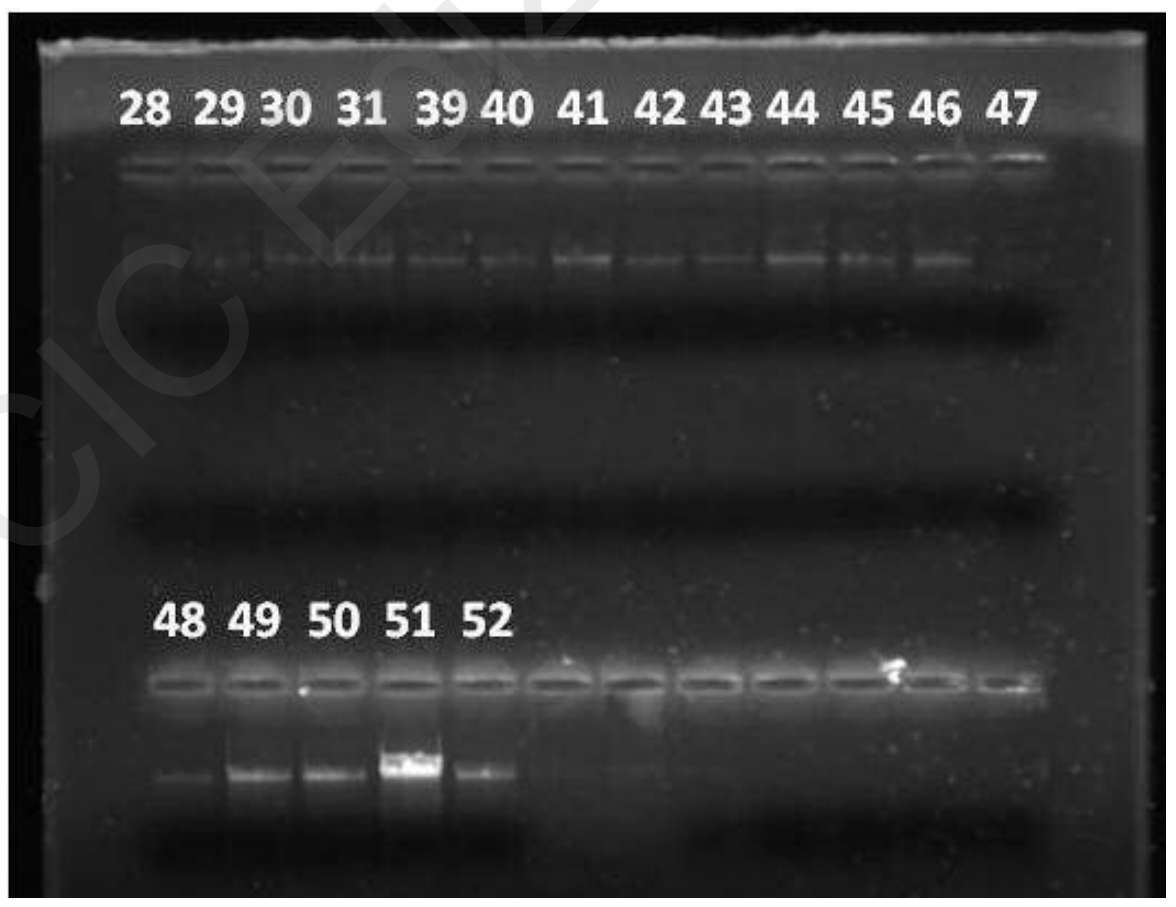

Figure 1. Genomic DNA isolated from PBMCs subjected to electrophoresis on $1 \%$ agarose gel for quality verification. 
Are COL1A1 gene polymorphisms associated with anterior cruciate ligament tear in the Indian population?

Results of a preliminary case-control study

ried out for $20 \mu \mathrm{L}$ solution (containing $10 \mu \mathrm{L}$ master mix, $5 \mu \mathrm{L}$ assay, $20 \mathrm{ng}$ DNA and $5 \mu \mathrm{L}$ molecular biology grade water). All these reactions were carried out using TaqMan®/SYBR ${ }^{\mathrm{TM}}$ Green pre-designed genotyping assays according to the manufacturers' recommendations. Both alleles in genotyping assay were tagged two reporter dyes namely VIC and FAM to detect the SNP changes at the particular locus. Software Step One ${ }^{\mathrm{TM}}$ v2.0 (Applied Biosystems, Foster City, USA) was utilised to perform amplification and to estimate SNPs followed by importing of the fluorescence $(R n)$ values recorded during the plate read using the Sequence Detection System (SDS) software. The DNA samples were genotyped for COL1A1 rs1800012 and rs1107946 SNPs using PCR amplification.

\section{Statistical analysis}

The SPSS (Statistical Package for the Social Sciences) software (version 16.0) was used for data analysis. Normal quantile (Q-Q) plots were constructed to check for the normality of the data distribution. Unpaired Student's $t$-test was used to test the association between cases and controls. Before proceeding to genotyping analysis, Hardy-Weinberg equilibrium was tested; the genotypes for each SNP were stratified for homozygosity and heterozygosity, and of the respective allelic variant. Pearson's chi-square test and Cochran-Mantel-Haenszel equation were applied for the genotyping result analysis.

\section{Results}

SNPs analysis of rs1800012 (Sp1 binding site) and rs1107946 of COL1A1

Frequency of both genotypes GT and TT of rs180 0012 locus haven't shown any significant association with ACL tear. Similarly, frequency of $T$ alleles $(p=0.5163)$ did not show any correlation with pathology. Conclusively, results of rs1800012 SNP analysis shown no statistically significant difference in both genotype as well as (Supplementary information Table I) $(p=0.516)$ between ACL and control groups (Tab. I, Fig. 2). All groups were in Hardy Weinberg equilibrium (HWE value $=0.11$.

Moreover, genotype (GT and TT $p=0.9711, p=0.8226$, respectively) of rs1107946 SNP did not reveal any association with ACL pathology as compare to controls. Additionally, genotype ad allele frequency (sup-

Table I. Effect of genetic variants of rs1800012 on ACL tear phenotype

\begin{tabular}{llllll}
\hline Genotype & Number & OR & $95 \% \mathrm{Cl}$ & Z- statistics & Value \\
\hline & ACL & Controls & & & \\
GG & 1 & 0 & Reference & & $*$ \\
GT & 7 & 7 & $*$ & $*$ & $*$ \\
TT & 39 & 43 & $*$ & $*$ & $*$ \\
\hline
\end{tabular}

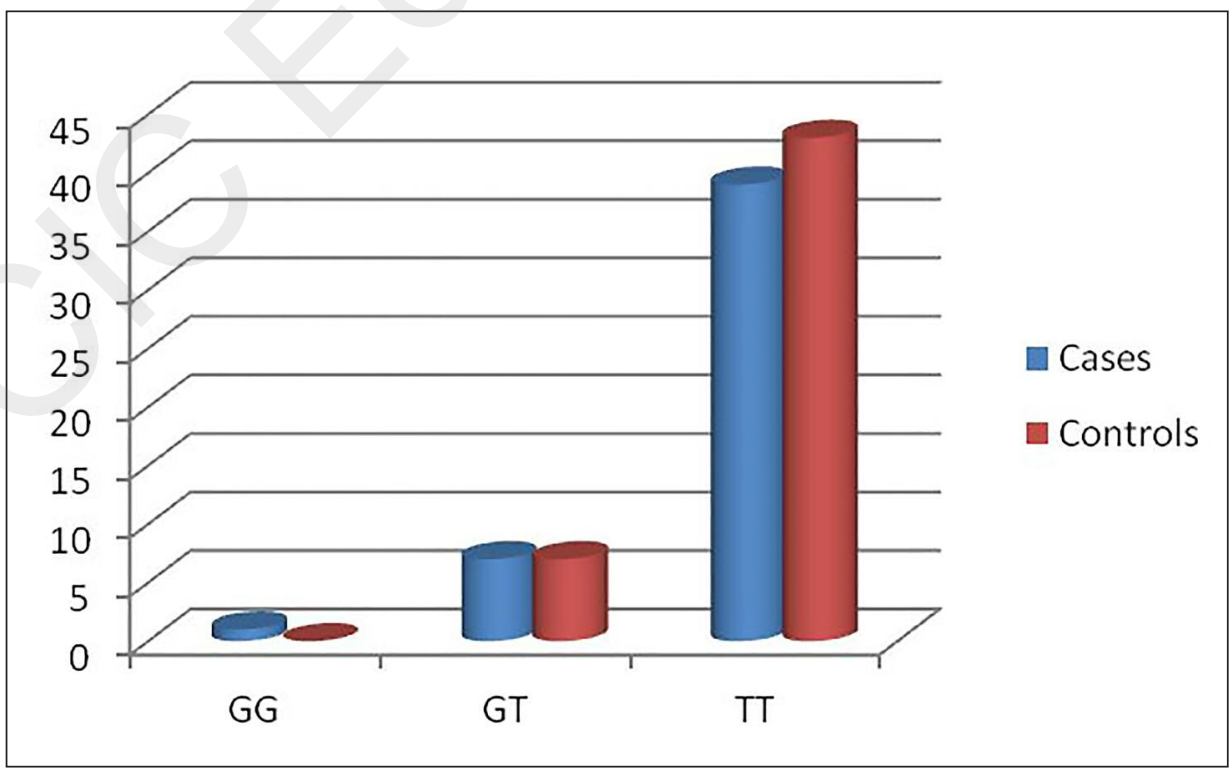

Figure 2. Graph depicting relative frequency of genotypes (GG, GT and TT) for rs18000012 polymorphism of COL1A1 gene. 
plementary information Tab. II) of the same locus has also not shown any statistical difference between ACL control groups $(p=0.7665)$ (Tab. II, Fig. 3).

\section{Discussion}

ACL tear has a complex, multifactorial etiology; an interaction between predisposing genetic factors, environmental and intrinsic risk factors has been proposed by multiple research groups ${ }^{3,4}$. Overall, 20 genes (33 different genetic variants) have been investigated for their association with ACL tear; out of these, 10 gene polymorphisms (SNPs) and 8 haplotypes have been linked to ACL tear ${ }^{5,6}$. Till date, four different research groups have tested for the association of COL1A1 polymorphisms with ACL tears (Tab. III) ${ }^{10-13}$. These studies linking gene polymorphisms to ACL tears are essential as these tests can be used to predict injury risk in athletes and alter clinical management protocols and training regimens in these "high-risk" individuals.

The ACL is predominantly made up of collagen protein
(75\%) which is encoded by different collagen genes; each type of collagen performs diverse functions ${ }^{14}$. The major structural collagen in ACL is type I collagen (comprising $70 \%$ to $80 \%$ of the dry mass of ACL). Type I collagen is a heterotrimer of two a1 and one a2 chains; these two chains are encoded by $C O L 1 A 1$ and COL1A2 genes respectively ${ }^{15}$. The COL1A1 gene is located on the long arm of chromosome 17 (17q21.3q22) whereas the $C O L 1 A 2$ gene is located on the long arm of chromosome 7 (7q22.1). The COL1A1 gene consists of 52 exons and is $18 \mathrm{~kb}$ in size ${ }^{16}$. It has been found that the substitution of $G$ to $T$ at the binding site of Sp1 (rs1800012) consequently led to enhanced expression of proteins concomitant with the increased binding affinity of Sp1. (Fig. 4) ${ }^{17}$.

The rs1107946 SNP is located in the proximal promoter region of COL1A1 gene at position -1997 relative to the transcription start site ${ }^{12}$. This SNP has been associated with bone mineral density (BMD) and has a role in the in vitro regulation of osteoblasts ${ }^{18,19}$. It has been investigated for an association with ACL tear susceptibility by Ficek et al. ${ }^{12}$ who reported no independent association.

Table II. Effect of genotypic variants of COL1A1 rs1107946 on ACL tear phenotype.

\begin{tabular}{lllllll}
\hline Genotype & Number & & OR & $95 \% \mathbf{C l}$ & Z- statistics & p-value \\
\hline GG & ACL & Control & & & & \\
GT & 7 & 8 & Reference & & & \\
TT & 17 & 19 & 1.023 & $0.306-3.419$ & 0.036 & 0.971 \\
\hline
\end{tabular}

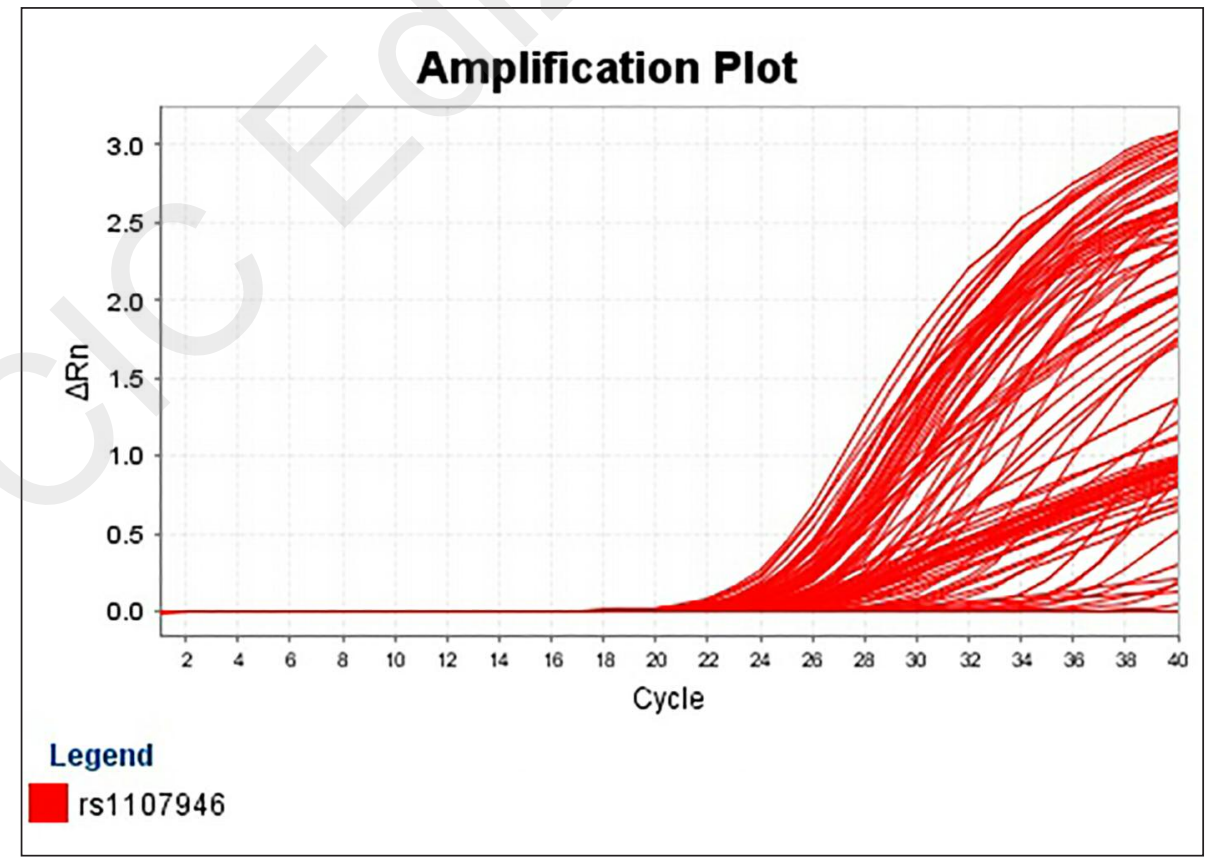

Figure 3. Representative amplification plot for ACL control and patient PBMCs from SNP genotyping analysis for rs1107946 variant. 
Are COL1A1 gene polymorphisms associated with anterior cruciate ligament tear in the Indian population?

Results of a preliminary case-control study

Table III. Summary of all studies investigating association of COL1A1 SNPs and ACL tear.

\begin{tabular}{|c|c|c|c|c|c|}
\hline Sno & $\begin{array}{l}\text { Authors } \\
\text { (Year) }\end{array}$ & Population & $\begin{array}{l}\text { SNP } \\
\text { analysed }\end{array}$ & Sample size & Salient Results of study \\
\hline 1 & $\begin{array}{l}\text { Khoschnau } \\
\text { et al. (11) } \\
2008\end{array}$ & Sweden & rs1800012 & $558(233)$ & $\begin{array}{l}\text { TT genotype of the rs } 1800012 \text { was shown to be } \\
\text { significantly under-represented in participants with } \\
\text { ACL tears (only } 1 \text { in } 233 \text { cases had this } \\
\text { genotype). The presence of TT genotype was } \\
\text { postulated to be protective against ACL tear. }\end{array}$ \\
\hline 2 & $\begin{array}{l}\text { Posthumus } \\
\text { et al. (10) } \\
2009\end{array}$ & South Africa & rs1800012 & $247(117)$ & $\begin{array}{l}\text { Under-representation of TT genotype in } \mathrm{ACL} \\
\text { group }(\mathrm{OR}=0.08(95 \% \mathrm{CI}, 10.01-1.46) ; \mathrm{p}=0.031)\end{array}$ \\
\hline 3 & $\begin{array}{l}\text { Stepien- } \\
\text { Slodkowska } \\
\text { et al. (13) } \\
2013\end{array}$ & Poland & rs1800012 & $366(183)$ & $\begin{array}{l}\text { Risk was } 1.43 \text { times lower in carriers of a minor } \\
\text { allele } G \text { as compared to carriers of the allele T } \\
\text { ( } p=0.045 \text { ). } \\
\text { No under-representation of the TT genotype } \\
\text { noted. }\end{array}$ \\
\hline 4 & $\begin{array}{l}\text { Ficek et al. } \\
\text { (12) } 2013\end{array}$ & Poland & $\begin{array}{l}\text { rs1800012 } \\
\text { rs1107946 }\end{array}$ & $234(91)$ & $\begin{array}{l}\text { No significant association of genotype/allele } \\
\text { distribution with ACL tear. } \\
\text { No under-representation of the TT genotype } \\
\text { noted. }\end{array}$ \\
\hline 5 & This study & India & $\begin{array}{l}\text { rs1800012 } \\
\text { rs1107946 }\end{array}$ & $102(50)$ & $\begin{array}{l}\text { No significant association of genotype/allele } \\
\text { distribution with ACL tear } \\
\text { No under-representation of the TT genotype } \\
\text { noted. }\end{array}$ \\
\hline
\end{tabular}

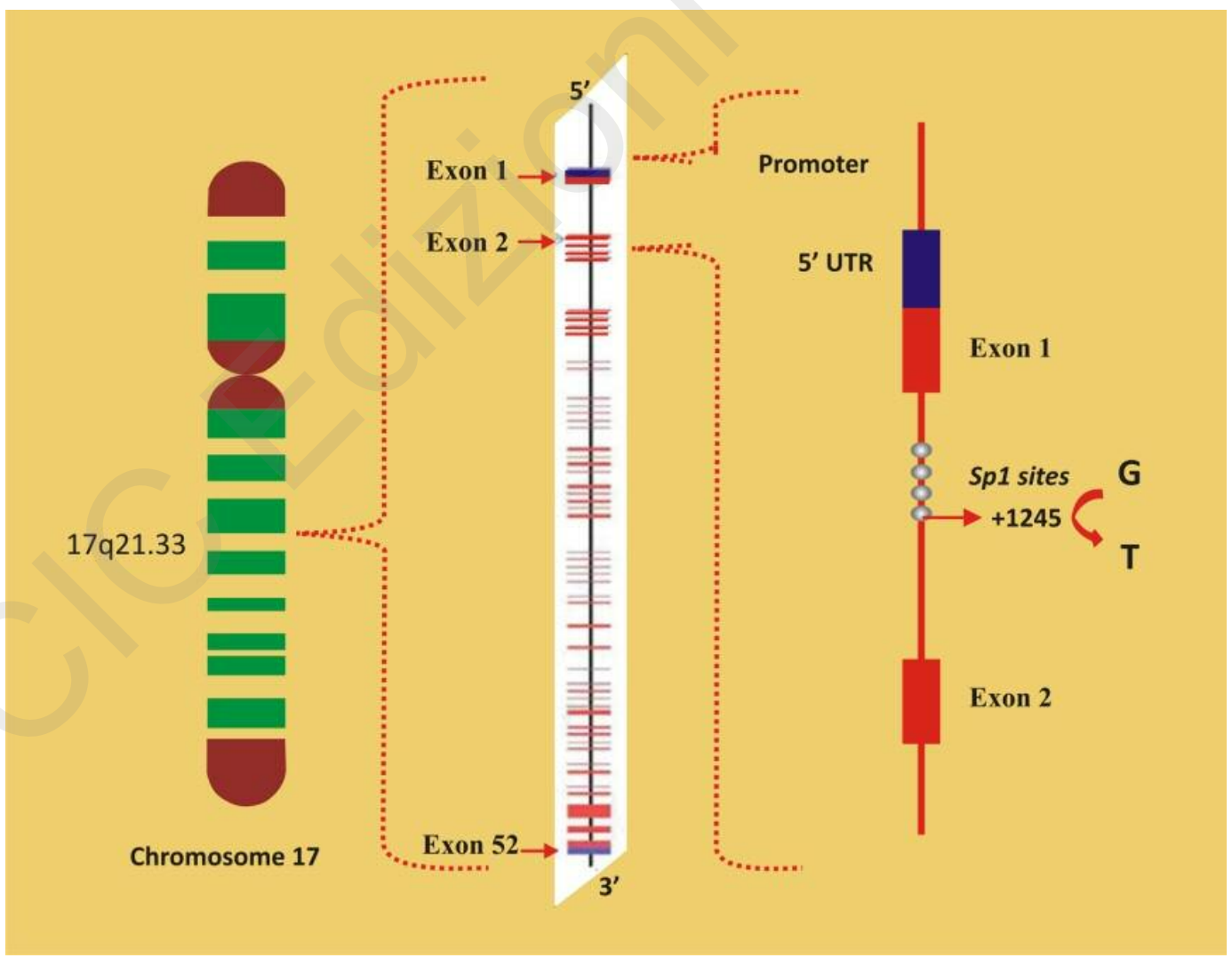

Figure 4. Diagrammatic representation of COL1A1 gene locus on chromosome 17, and functional polymorphism at the Sp1 site from guanine $(G)$ to thymidine $(T)$. 
Although a familial predisposition to $A C L$ tear was postulated by Harner et al. ${ }^{20}$ and Flynn et al. ${ }^{1}$, Khoschnau et al. ${ }^{11}$ were the first to investigate for a specific gene polymorphism linked to ACL tear. They reported that the TT genotype of the rs1800012 polymorphism was significantly under-represented in patients with cruciate ligament tears and shoulder dislocations ${ }^{11}$. Posthumus et al. have investigated the genetic association of rs1800012 (COL1A1) in 117 Caucasian ACL individuals (surgically diagnosed) and 113 controls. Results have demonstrated the lack of TT genotype in ACL participants (zero in $117 \mathrm{ACL}$ individual) as compared to controls (6 in 113 individuals) $(p=0.031)$. The results have suggested the imperative role of TT genotype in ACL pathology.

Stepien-Slodkowska et al. ${ }^{13}$ tested 321 male skiers (138 cases and 183 controls) for the association of rs18000012 polymorphism with ACL tear. Results showed 1.43 times lower risk of ACL tear was observed in $G$ allele as compared to $T$ allele in the $A C L$ individuals $(p=0.045)$. However, they did not observe under-representation of the TT genotype in the ACL group unlike the previous two studies ${ }^{10,11 .}$

Ficek et al. ${ }^{12}$ tested both rs1800012 and rs1107946 SNPs for their association with ACL tear in 377 male Polish soccer players (234 cases and 143 controls). They observed that both these SNPs were not significantly associated with ACL tear $(p=0.228$ for rs1107946 and $p=0.138$ for $r s 1800012$ polymorphism). However, on performing a further haplotype analysis of these two SNPs, they noted that a higher frequency of the COL1A1 G-T (rs1800012 and rs1107946) haplotype expression was significantly associated with decreased risk of ACL tear (haplotype score, $-1.98 ; p=0.048)^{12}$. It is to be noted that both these Polish studies were exclusively limited to male populations and therefore it was not possible to ascertain gender-specific association unlike Posthumus et al. ${ }^{10}$.

Due to a non-Mendelian inheritance pattern, the association between COL1A1 SNPs and ACL tear is quite complex unlike the Mendelian-inherited genetic diseases of COL1A1 gene (e.g.: osteogenesis imperfecta) ${ }^{15,17,21}$. Complex gene-gene and gene-environment interactions alter the severity of the phenotype in non-Mendelian pattern inherited conditions like ACL tear $^{7,21}$. Recently, Yao et al. linked the rs1107946 polymorphism to the geometric size of ACL in the Chinese population ${ }^{22}$. Bell et al. ${ }^{23}$ have linked the rs1800012 polymorphism to increased knee joint laxity. Both geometric size of ACL and joint laxity are individual intrinsic risk factors for $A C L$ tear; therefore, COL1A1 SNPs may predispose a person to an ACL tear in more ways than one.

It is also interesting to note that, COL1A1 SNPs have also been associated with other sports injuries like Achilles tendinopathy, tennis elbow and shoulder dislocations ${ }^{11,17,23,25}$. Wang et al. examined association of SNPs and sports-related ligament and tendon COL1A1 injuries (like ACL tear, Achilles tendinopathy, tennis elbow and should dislocation). They observed that the rare TT genotype may be protective against these sports-related ligament/tendon injuries $^{7}$. Apart from sports injuries, the rs18000012 SNP of COL1A1 gene has most notably been linked to osteoporosis; various other complex disorders of connective tissue, including, myocardial infarction, lumbar disc disease and stress urinary incontinence have also shown association with this SNP26-29.

Our study showed that COL1A1 rs1800012 and rs1107946 polymorphisms were present in the Indian population, follow the Hardy-Weinberg equilibrium but do not seem to be associated with ACL tear. This is similar to the results obtained by Ficek et al. ${ }^{12}$ in the Polish population. There was no underrepresentation of the TT genotype in patients with ACL tear in the Indian population subset as noted by Posthumus et al. ${ }^{10}$ and Khoschnau et al. ${ }^{11}$ in South African and Swedish Caucasian populations respectively.

This is the first study from Asia to test the association between ACL tear and COL1A1 gene polymorphisms. Malila et al. ${ }^{30}$ have conducted the only other Asian genetic association study for ACL tear. They studied the association between matrix metalloproteinase (MMP) genes and ACL tears and observed no significant association ${ }^{30}$. It is to be noted that all other COL1A1 genetic association studies have been performed on Caucasian study subjects ${ }^{10-13}$. There are, however, a few limitations of this study. Most of the patients are from the northern region of India and the results could vary significantly if patients from other parts of the country are tested. The sample size is relatively small compared to similar studies; however, this is a preliminary study of a larger ongoing research project. Also, the number of female participants in the study was less; however, the primary objective of the study was not to look for gender-specific association.

\section{Conclusion}

In conclusion, this study found that there is no significant association between rs1800012 and rs11079846 polymorphism frequencies with $\mathrm{ACL}$ tear in the Indian population unlike most other Caucasian studies. Genetic research studies and tests will pave the way for customised preventive measures and personalised nutrition, training regimens to help reduce the incidence of ACL tears ${ }^{31}$. However, we believe that larger studies in different ethnic populations are needed across the world to define the association of this specific sequence variant with ACL tear before incorporating these genetic screening tests in an $A C L$ tear preventive model. 
Are COL1A1 gene polymorphisms associated with anterior cruciate ligament tear in the Indian population? Results of a preliminary case-control study

\section{Author's contribution}

SP: Principle investigator, co-conceptualization of study, editing of manuscript, and recruitment of participants; RJ: Recruitment of participants and writing of manuscript; MSD: Editing of manuscript and co-conceptualization of study; KS: Experimentations and editing of manuscript; SB: Samples process and experimentation of the study; AA: Principle investigator, coconceptualization of study and editing of manuscript.

\section{Conflict of interest}

All Authors have expressed no conflict of interest persist in any part of the study.

\section{Acknowledgements}

We highly appreciate and acknowledge the individuals who participated in the study and provide their consent to use their samples to conduct the study.

\section{References}

1. Flynn RK, Pedersen CL, Birmingham TB, Kirkley A, Jackowski D, Fowler PJ. The familial predisposition toward tearing the anterior cruciate ligament. Am J Sports Med. 2005;33(1):2328.

2. John R, Dhillon MS, Syam K, Prabhakar S, Behera P, Singh H. Epidemiological profile of sports-related knee injuries in northern India: An observational study at a tertiary care centre. J Clin Orthop Trauma. 2016;7(3):207-211.

3. Smith HC, Vacek P, Johnson RJ, Slauterbeck JR, Hashemi J, Shultz S, et al. Risk factors for anterior cruciate ligament injury: a review of the literature? Part 1: neuromuscular and anatomic risk factors, Sports Health. 2012;4(1):69-78.

4. Smith HC, Vacek P, Johnson RJ, Slauterbeck JR, Hashemi J, Shultz S, et al. Risk Factors for Anterior Cruciate Ligament Injury: A Review of the Literature - Part 2: Hormonal, Genetic, Cognitive Function, Previous Injury, and Extrinsic Risk Factors, Sports Health. 2012;4(2):155-161.

5. Kaynak M, Nijman F, van Meurs J, Reijman M, Meuffels DE. Genetic variants and anterior cruciate ligament rupture: A systematic review. Sports Med (Internet). 2017. Available from: http://link.springer.com/10.1007/s40279-017-0678-2

6. John R, Dhillon MS, Sharma S, Prabhakar S, Bhandari M. Is there a genetic predisposition to anterior cruciate ligament tear? A systematic review, Am J Sports Med. 2016;44(12): 3262-3269.

7. Wang C, Li H, Chen K, Wu B, Liu H. Association of polymorphisms rs 1800012 in COL1A1 with sports-related tendon and ligament injuries: a meta-analysis. Oncotarget (Internet) 2017. Available from: http://www.oncotarget.com/abstract/15271.

8. Maffulli N, Margiotti K, Longo UG, Loppini M, Fazio VM, Denaro $V$. The genetics of sports injuries and athletic performance. MLTJ. 2013;3(3):173-189.

9. Padulo J, Oliva F, Frizziero A, Maffulli N. Muscles, Ligaments and Tendons Journal - Basic principles and recommendations in clinical and field science research: 2016 update. MLTJ. 2016;6(1):1-5.
10. Posthumus M, September AV, Keegan M, O'Cuinneagain D, Van der Merwe W, Schwellnus MP, et al. Genetic risk factors for anterior cruciate ligament ruptures: COL1A1 gene variant, Br J Sports Med. 2009;43(5):352-356.

11. Khoschnau S, Melhus $\mathrm{H}$, Jacobson $\mathrm{A}$, Rahme H, Bengtsson $\mathrm{H}$, Ribom E, et al. Type I collagen a 1 Sp1 polymorphism and the risk of cruciate ligament ruptures or shoulder dislocations, Am J Sports Med. 2008;36(12):2432-2436.

12. Ficek K, Cieszczyk P, Kaczmarczyk M, Maciejewska-Karłowska A, Sawczuk M, Cholewinski J, et al. Gene variants within the COL1A1 gene are associated with reduced anterior cruciate ligament injury in professional soccer players. J Sci Med Sport. 2013;16(5):396-400.

13. Stepien-Slodkowska M, Ficek K, Eider J, Leolska-Duniec A, Maciejewska-Karlowska A, Sawczuk M, et al. The $+1245 \mathrm{G} / \mathrm{T}$ polymorphisms in the Collagen type I alpha 1 (COL1A1) gene in Polish skiers with anterior cruciate ligament injury. Biol Sport. 2013;30(1):57-60.

14. Frank CB. Ligament structure, physiology and function. J Musculoskelet Neuronal Interact. 2004;4(2):199-201.

15. Myllyharju J, Kivirikko KI. Collagens and collagen-related diseases. Ann Med. 2001;33(1):7-21.

16. Anjankar S, Poornima S, Raju S, Jaleel M, Bhiladvala D, Hasan Q. Degenerated intervertebral disc prolapse and its association of collagen I alpha $1 \mathrm{Spl}$ gene polymorphism: A preliminary case control study of Indian population. Indian J Orthop. 2015;49(6):589.

17. Collins M, Posthumus M, Schwellnus MP. The COL1A1 gene and acute soft tissue ruptures. Br J Sports Med. 2010;44(14): 1063-1064.

18. Yazdanpanah N, Rivadeneira F, van Meurs JBJ, Zillikens MC, Arp P, Hofman A, et al. The $-1997 \mathrm{G} / \mathrm{T}$ and Sp1 polymorphisms in the collagen type I alpha1 (COLIA1) gene in relation to changes in femoral neck bone mineral density and the risk of fracture in the elderly: the Rotterdam study, Calcif Tissue Int. 2007;81(1):18-25.

19. García-Giralt N, Enjuanes A, Bustamante M, Mellibovsky L, Nogués $\mathrm{X}$, Carreras $\mathrm{R}$, et al. In vitro functional assay of alleles and haplotypes of two COL1A1-promoter SNPs, Bone. 2005;36(5):902-908.

20. Harner CD, Paulos LE, Greenwald AE, Rosenberg TD, Cooley VC. Detailed analysis of patients with bilateral anterior cruciate ligament injuries. Am J Sports Med. 1994;22(1):37-43.

21. van Heyningen V. Mechanisms of non-Mendelian inheritance in genetic disease. Hum Mol Genet. 2004;13(Supl 2):R225233.

22. Yao C, Zhu B, Liu Y, Xu X, Yang X, Xu Z et al. Association of MMP3 COL5A1 and COL1A1 gene polymorphisms with ACL geometric size in Chinese population. Int $\mathrm{J}$ Clin Exp Pathol. 2017;10(2):1991-1997.

23. Bell RD, Shultz SJ, Wideman L, Henrich VC. Collagen gene variants previously associated with anterior cruciate ligament injury risk are also associated with joint laxity, Sports Health. 2012;4(4):312-318.

24. Erduran M, Altinisik J, Meric G, Ates O, Ulusal AE, Akseki D. Is Sp1 binding site polymorphism within COL1A1 gene associated with tennis elbow? Gene. 2014;537(2):308-311.

25. Posthumus M, September AV, Schwellnus MP, Collins M. Investigation of the Sp1-binding site polymorphism within the COL1A1 gene in participants with Achilles tendon injuries and controls. J Sci Med Sport. 2009;12(1):184-189.

26. Mann V, Hobson EE, Li B, Stewart TL, Grant SF, Robins SP, et al. A COL1A1 Sp1 binding site polymorphism predisposes to osteoporotic fracture by affecting bone density and quality. J Clin Invest. 2001;107(7):899-907. 
27. Speer G, Szenthe P, Kósa JP, Tabák AG, Folhoffer A, Fuszek $P$, et al. Myocardial infarction is associated with Spl binding site polymorphism of collagen type $1 \mathrm{~A} 1 \mathrm{gene}$. Acta Cardiol. 2006;61(3):321-325.

28. Tilkeridis C, Bei T, Garantziotis S, Stratakis CA. Association of a COL1A1 polymorphism with lumbar disc disease in young military recruits. J Med Genet. 2005;42(7):e44.

29. Skorupski P, Król J, Starega J, Adamiak A, Jankiewicz K Rechberger T. An alpha-1 chain of type I collagen Sp1-binding site polymorphism in women suffering from stress urinary incontinence. Am J Obstet Gynecol. 2006;194(2):346-350.

30. Malila S, Yuktanandana P, Saowaprut S, et al. Association between matrix metalloproteinase-3 polymorphism and anterior cruciate ligament ruptures, Genet Mol Res. 2011;10(4): 41584165.

31. Goodlin GT, Roos AK, Roos TR, Hawkins C, Beache S, Baur $\mathrm{S}$, et al. Applying personal genetic data to injury risk assessment in athletes. PLOS ONE 2015;10(4):e0122676. 